\title{
Characterization of the defence response to Venturia inaequalis in 'Honeycrisp' apple, its ancestors, and progeny
}

\author{
Matthew D. Clark • Vincent G. M. Bus • \\ James J. Luby • James M. Bradeen
}

Accepted: 30 April 2014 / Published online: 17 May 2014

(C) The Author(s) 2014. This article is published with open access at Springerlink.com

\begin{abstract}
The apple cultivar Honeycrisp exhibits genetic resistance to apple scab. The characterization of the macroscopic and microscopic responses on leaves infected by the pathogen Venturia inaequalis is described. The macroscopic resistance reactions observed in 'Honeycrisp', its parent 'Keepsake', and grandparents 'Frostbite' and 'Northern Spy' ranged from 0 (no reaction) to chlorotic flecking, stellate chlorosis, necrotic flecking, and sporulation. No hypersensitive response was observed. The resistance response occurred as early as 7 days post inoculation (dpi) at the same time that susceptible plants exhibited macroscopic signs of the disease. The resistance reactions were similar in the progeny population of 'Honeycrisp' $\times$ 'Twin Bee Gala', although they were delayed to 10-14 dpi possibly due to variable greenhouse conditions. This population segregated 3 resistant: 1 susceptible, which suggests the presence of two genes in 'Honeycrisp' and agrees with the finding that different responses within 'Honeycrisp'
\end{abstract}

M. D. Clark · J. J. Luby $(\bowtie)$

Department of Horticultural Science,

University of Minnesota,

St. Paul, MN, USA

e-mail: lubyx001@umn.edu

V. G. M. Bus

The New Zealand Institute for Plant \& Food Research Limited,

Private Bag 1401, Havelock North 4157, New Zealand

J. M. Bradeen

Department of Plant Pathology, University of Minnesota,

St. Paul, MN, USA to mixed inoculum are due to differential recognition of pathogen effectors.

Keywords Venturia inaequalis · Apple scab · Malus · Malus-Venturia Pathosystem

\section{Introduction}

The ascomycete Venturia inaequalis (Cke.) Want. is a plant pathogen of apple (Malus spp.) in production areas worldwide. The disease caused by the fungus, commonly known as apple scab, is evident on leaves and can negatively affect plant health, habit, and growth. More importantly, symptoms develop on fruit which render them unsalable to many fresh markets. In the orchard, the symptoms first develop in early spring from primary infections caused by ascospores that are released from pseudothecia in leaf litter. The first ascospore release often coincides with bud break when the host tissue is most vulnerable and the environmental conditions are highly favourable. The ascospores are moved into air currents during rain events. With appropriate weather conditions, the ascospores germinate on young leaves, penetrate the cuticle, and develop into subcuticular stromal that eventually produce conidiophores which rupture the cuticle. Mycelia, conidiophores, and asexual spores called conidia develop resulting in circular green to brown "scab" lesions on infected leaves. The conidia are capable of causing secondary infections on leaves and fruit, and are dispersed throughout the tree canopy through rain and water droplets. 
Resistance breeding provides a preferred avenue to controlling the disease. To date, $17+\mathrm{R}$ genes mediating Malus- $V$. inaequalis interactions have been described (Gessler et al., 2006; Bus et al., 2011; Jha et al., 2009). These genes each impart pathogen race-specific resistance following the gene-for-gene model first described by Flor (1956). The model defines the incompatible interaction in which the $R$ locus is present in the host and the cognate $A v r$ locus is present in the pathogen, resulting in a disease resistance phenotype in the host (Dangl and Jones, 2001). Vanderplank (1978) defined the model as a protein-for-protein interaction, which more accurately describes the interaction of the pathogen effector's AVR protein and the host $\mathrm{R}$ gene protein (s).

Resistant and susceptible plants are each capable of mounting a defence response, however, the lack of detection of the pathogen effector allows the fungus to colonize susceptible leaves and fruit (Boone, 1971). The initial stages of infection starting with spore germination, appressoria development, penetration of the cuticle, and hyphal development are similar in resistant and susceptible cultivars (Nicholson, 1977; Komjanc et al., 1999). The cuticle is not a barrier to the pathogen (Valsangiacomo and Gessler, 1988). Any subsequent resistance reaction falls within a continuum from complete resistance [hypersensitive response (HR)] to complete susceptibility (sporulating lesions) depending on the resistance genes, pathogen race, and incubation conditions (Shay and Hough, 1952). Ontogenic resistance in older leaves prevents infection in these tissues, and the development of stromal, colonization and sporulation are slowed in progressively older leaves, although spore germination and appressoria development occur at the same rate (Gessler and Stumm, 1984).

The HR in apple is conditioned by several previously described R genes including Rvi4 (Vh4 $=V x=V r l)$, Rvi5 (Vm), Rvi7 (Vfh), Rvi10 (Va), Rvi15 (Vr2) and Rvil6 (Vmis) (Win et al., 2003; Galli et al., 2010; Bus et al., 2011). This "pin-point" reaction results from the rapid death and subsequent collapse of cells immediately surrounding the penetration site of the spore (Goodman and Novacky, 1994). The HR is visible to the naked eye as small depressions on the leaf surface that extends from the upper to lower leaf surface and are visible on abaxial and adaxial surfaces (Nicholson et al., 1973). The HR has been well characterized in fixed and cleared leaf tissue (Chevalier et al., 1991; Galli et al., 2010). Although classically understood to be an immediate host response to pathogen attack, the HR observed in Malus-Venturia pathosystem has varied rates of reaction depending on the $\mathrm{R}$ gene present. Reaction times range from 2-11 days (Shay and Hough, 1952; Galli et al., 2010; Bowen et al., 2011). The HR prevents colonization through programmed cell death (PCD) and may involve cell to cell signalling mediated in part by reactive oxygen species. Not all components of the PCD are known, but various phytoalexins and the accumulation and oxidation of other phenolic compounds (phloridzin and phloretin) have been implicated in the HR (Nicholson, 1977).

Early studies of apple leaf and peel tissues to infection by $V$. inaequalis and Podosphaera leucotricha (powdery mildew) exhibited increased concentrations of fluorescent phenolic compounds as part of the host response in both resistant and susceptible interactions (Barnes and Williams, 1960). Investigations of plantpathogen interactions in other pathosystems provide additional support that the phenolic compounds that auto-fluoresce under ultraviolet light provide a convenient research tool to document the presence of the HR (Heath et al., 1997). HR also results in structural cellular changes including granulation of the cytoplasm (Nicholson, 1977). The microscopic wound caused by PCD can leave the leaf vulnerable to other opportunistic secondary infections, and it is proposed that fluorescence may be due to the accumulation of rigid chemical compounds, such as phyotalexins (Vanderplank, 1982). Lignification of cell walls also occurs in cells surrounding an infection site, reducing the risk of water loss and secondary infections (Holzapfel et al. 2012).

In addition to the HR, other resistance phenotypes have been observed in the Malus-Venturia pathosystem. These include chlorosis (chlorotic flecking), stellate chlorosis, and stellate necrosis (Bowen et al., 2011). Necrotic flecking is also observed in some reactions (Bénaouf and Parisi, 2000; Dunemann and Egerer, 2010). Chevalier et al. (1991), following earlier phenotypic scales for evaluating resistance (Shay and Hough, 1952), developed a six point macroscopic scale to describe resistance induced by Rvi6 (Vf). The symptoms range from: no lesions (0), HR (1), chlorotic lesions (2), necrotic/chlorotic lesions with slight sporulation (3a-weak resistance), necrotic/chlorotic lesions with sporulation (3b-weak susceptibility), and lesions with high sporulation (4) (Chevalier et al. 1991). The differences observed in a progeny population among those containing the $\mathrm{R}$ gene is the result of isolate 
virulence and minor or modifying genes that are also segregating in the host population (Lamb and Hamilton, 1969; Williams and Kuc, 1969; Gessler, 1992; Gardiner et al., 1996).

Recently, Berkett et al. (2009) identified resistance in the emerging apple cultivar 'Honeycrisp' grown under organic disease management, which findings led to the current microscopic and macroscopic investigation of the resistance reaction. Here we report on the resistance reaction in 'Honeycrisp' and its putative ancestors to inoculation with a mixed conidial suspension of Minnesota $V$. inaequalis isolates in a greenhouse environment. A subset of a seedling progeny population of 'Honeycrisp' $\times$ 'Twin Bee Gala' was also evaluated using single spore isolates in the greenhouse.

\section{Materials and methods}

Two key experiments were conducted to elucidate and describe the defence responses in 'Honeycrisp' and its relatives. In the first experiment, the resistance reaction in the 'Honeycrisp' pedigree, including one seedling offspring, 'Minneiska' were evaluated. Figure 1 displays the putative 'Honeycrisp' pedigree (Cabe et al., 2005), including one progeny population ('Honeycrisp' $\times$ 'Twin Bee Gala'; $n=125$ ), and other individuals utilized in this study. Known R genes carried by these individuals are specified. Reference accessions screened in this study were 'Golden Delicious', 'Pristine',
M. floribunda 821, and 'Budagovsky 9', 'Minnewashta' and 'Royal Gala'.

\section{Experiment 1}

The cultivars utilized in this study were grown on 'Budagovsky 9' rootstock and maintained in greenhouses at the University of Minnesota-Twin Cities Campus, St. Paul, MN. Single spore $V$. inaequalis isolates of unknown race (Table 1) derived from infected leaves and fruit from unknown crab apples, advanced breeding material, and named cultivars (Minnewashta and Minneiska) from orchards at the Horticultural Research Center, Excelsior and Chaska, MN, the North Central Research and Outreach Center, Grand Rapids, MN, and a residential neighborhood in Minneapolis, MN, were grown in axenic conditions on potato dextrose agar (39 $\mathrm{g} \mathrm{l}^{-1}$; Oxoid, LTD, Basingstoke, Hampshire, England) modified with $50 \mathrm{mg}^{-1}$ Rifamycin SV sodium salt (MP Biomedicals, LLC, Solon, OH, USA) (Parker et al., 1995; Barbara et al., 2008). Isolates were tested separately for virulence and then bulked-up on susceptible young seedlings and stored on dried leaves at $-20{ }^{\circ} \mathrm{C}$ (Bus et al. 2005a, b). A mixed inoculum was made with equal spore concentrations of each isolate in deionized water and diluted to $10^{5}$ conidia $\mathrm{ml}^{-1}$. A positive control consisted of a single spore isolate $\mathrm{HC} 12 \mathrm{a}\left(10^{5}\right.$ conidia $\mathrm{ml}^{-1}$ ) derived from 'Honeycrisp' leaves collected at the Horticultural Research Center, Chaska, MN. Conidia

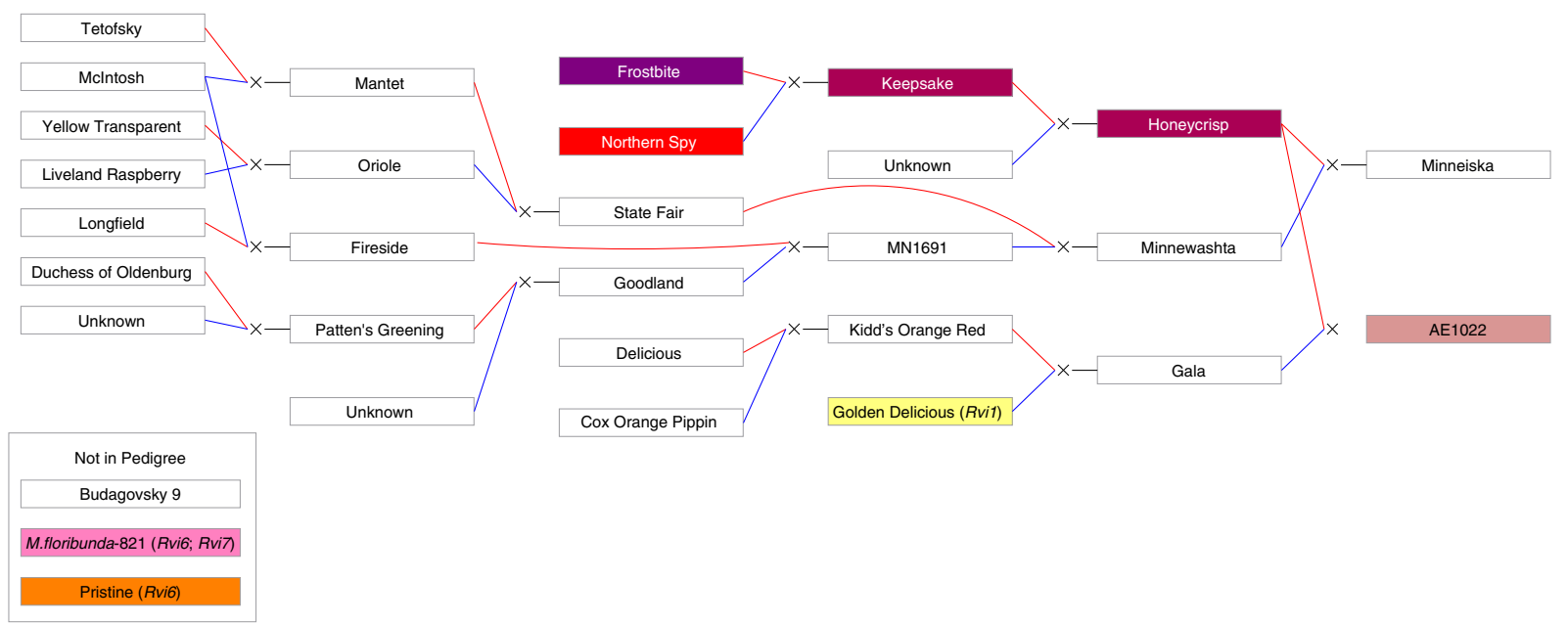

Fig. 1 'Honeycrisp' pedigree including the 'Honeycrisp' $\mathrm{x}$ 'Twin Bee Gala' population (AE1022). Highlighted individuals indicate those with known resistance genes (Rvi) or the proposed 'Honeycrisp' (red, purple) resistance currently under investigation.
Individuals separate from the pedigree were included in the experiment for phenotypic observations (Pedigree constructed using Pedimap (Voorrips et al., 2012)) 
Table 1 Venturia inaequalis monoconidial isolates, originating lesion tissue, host genotype, collection location, and collection year for isolates pooled into mixed inoculum utilized in Experiment 1 for characterizing the apple scab resistance reaction in 'Honeycrisp'

\begin{tabular}{lllll}
\hline Isolate & Origin & Genotype & Location & Year \\
\hline 1731 & Fruit & MN1731 & Grand Rapids, MN & 2010 \\
1914C & Leaf & Minneiska & Chaska, MN & 2010 \\
1914D* & Leaf & Minneiska & Chaska, MN & 2010 \\
80WA & Fruit & unknown & Excelsior, MN & 2010 \\
GR19142b* & Fruit & Minneiska & Grand Rapids, MN & 2010 \\
GR1914a & Fruit & Minneiska & Grand Rapids, MN & 2010 \\
Manchurian & Leaf & Manchurian & Chaska, MN & 2010 \\
MplsCrabd & Leaf & unknown & Minneapolis, MN & 2010 \\
ZestarFruit & Fruit & Minnewashta & Chaska, MN & 2010 \\
HC12a** & Fruit & Honeycrisp & Chaska, MN & 2012 \\
\hline
\end{tabular}

* Single spore isolates also used in Experiment 2 for screening 'Honeycrisp' x 'Twin Bee Gala' progeny population

** Single spore isolate used as a control

were harvested from this isolate directly from sporulating plates and not tested on seedlings.

Shoots with newly unfurled leaves (2-4 leaves) were inoculated by hand spraying until run-off with a conidial suspension of mixed $V$. inaequalis isolates. Plants had multiple stems and replicate trees were used, when available, for each inoculum treatment. Trees were placed into a dew chamber at $\sim 20{ }^{\circ} \mathrm{C}$ with relative humidity near $100 \%$ for $48 \mathrm{~h}$ to maintain leaf wetness. Following this infection period, trees were maintained in a greenhouse with intermittent mist to favour disease conditions ( $\mathrm{RH}$ $\sim 80 \%$ ). Insect pests (thrips and spider mites) were controlled with applications of insecticides prior to inoculation. The two youngest leaves from day 0 were collected from each genotype at 1, 3, 5, 7, 8, 9,10 , and 14 days post inoculation (dpi) and microand macroscopic evaluations were conducted as described below. This experiment commenced on 21 April 2013 and was replicated on 02 June 2013. A third replicate was conducted on 13 April 2013 with a limited number of genotypes ('Frostbite', 'Northern Spy', 'Keepsake', 'Honeycrisp' and 'Minnewashta') to elicit and evaluate a response in 'Keepsake', which had been infected with other pathogens in replications 1 and 2 .

Leaves were evaluated macroscopically for the presence of resistance reactions and/or evidence of mycelia or sporulation at each time point post inoculation. Leaves with evidence of insect feeding damage were not included in evaluations. Photographs of whole leaves were taken to document disease progression and resistance reactions. A binocular dissecting microscope was utilized to photograph macroscopic symptoms with increased magnification (Nikon SMZ800 with DS-2 camera and Digital Sight DS-L2; Nikon Instruments Inc., Melville, NY). Leaf samples were cleared and stained in $1.6 \mathrm{ml}$-microcentrifuge tubes following the protocol described by Galli et al. (2010). Cleared leaf samples were stored and mounted in $50 \%$ ethanol: $50 \%$ lactic acid for observation under a light microscope and in the auto-fluorescence interference blue range using the UV lamp (420-490 nm excitation filter, dichroic mirror $510 \mathrm{~nm}$, barrier filter $515 \mathrm{~nm}$ (Ernst Leitz Wetzlar 307-143.004 microscope; Ernst Leitz Wetzlar $\mathrm{GmbH}$, Germany). Photographs were obtained using a SPOT Insight 4 camera and accompanying SPOTBasic software (SPOT Imaging Solution, Sterling Heights, MI). Photographs were compiled and scale bars inserted in ImageJ software (Schneider et al., 2012).

\section{Experiment 2}

A seedling mapping population (AE1022, $n=121$ ) from a cross of 'Honeycrisp' $\times$ 'Twin Bee Gala' was evaluated for macroscopic resistance reactions (pedigree shown in Fig. 1). Seedling trees were inoculated with a single-spore conidial suspension $\left(7.5 \times 10^{5}\right.$ conidia $\left./ \mathrm{ml}\right)$ by hand spraying until leaf wetness resulting in run-off with single spore isolates GR19142b and 1914D (Table 1). Trees were placed into a dew chamber at $\sim 20{ }^{\circ} \mathrm{C}$ with relative humidity near $100 \%$ for $48 \mathrm{~h}$ to maintain leaf wetness. Following this infection period, trees were maintained in a greenhouse with intermittent mist to favour disease conditions ( $\mathrm{RH} \sim 80 \%$ ). After 10 14 days, symptoms were assessed using a 6 point scale: (0), HR (1) chlorotic lesions (2), necrotic/chlorotic lesions with slight sporulation (3a-weak resistance), necrotic/chlorotic lesions with sporulation (3b-weak susceptibility), and lesions with high sporulation (4) (Chevalier et al. 1991). Data were collected on the segregation of the symptom classes and segregation ratios were calculated for the population. Whole leaf photographs were taken from a subset of the progeny selected for their distinct resistance reaction to document the range of resistance reactions observed. 


\section{Results}

\section{Experiment 1}

Microscopic observations of leaves at 1-5 dpi showed the presence of conidia from the inoculum on the leaf surfaces, including the development of the germ tubes and appressoria in both compatible and incompatible reactions in inoculations from the mixed isolate suspension only. Macroscopic observations yielded no signs or symptoms of the pathogen until 7-8 dpi when scab lesions were detected on compatible host plants and a resistance reaction was evident on some incompatible host plants. Table 2 describes the reaction for each of the cultivars in the study. There was no evidence of germination or infection in the control inoculation with the single-spore isolate $\mathrm{HC} 12 \mathrm{a}$ throughout the experiment despite the confirmed microscopic presence of conidia. The lack of pathogenicity may be due to changes which occur in the pathogen while in culture (Nusbaum and Keitt, 1938), or alternatively, the HC12a conidia may have been dead.

'Keepsake", the putative 'Honeycrisp' parent, was infected with powdery mildew in the first replication

Table 2 Macro- and microscopic characterization of genotypes screened in the greenhouse with a mixed inoculum of Venturia inaequalis single spore isolates observed at several time points over two replications. The symptoms range from no lesions $(0)$, hypersensitive response (1), chlorotic lesions (2), necrotic/chlorotic lesions with slight sporulation (3a-weak resistance), necrotic/ of Experiment 1, which made it difficult to distinguish resistance reactions specifically from $V$. inaequalis. The second replication of the experiment resulted in numerous older leaves showing symptoms of bacterial infection in that cultivar. Leaves for observation in replication 2 were chosen based on limited or no bacterial lesions on that shoot or specific leaf. In the second and third replications, 'Honeycrisp' and its ancestors (including 'Keepsake') all displayed resistance reactions.

The macroscopic resistance reactions observed on 'Honeycrisp', 'Keepsake', 'Frostbite' and 'Northern Spy' were characterized as 2-3a (chlorotic flecking, stellate chlorosis, slight sporulation) as early as $7 \mathrm{dpi}$ in the second replication of the experiment and 8 dpi in the first replication. Visible browning, an indication of possible necrosis of leaf tissue was apparent after $10 \mathrm{dpi}$ in 'Honeycrisp' and increased by $14 \mathrm{dpi}$. The 'Northern Spy' reaction had evidence of stellate necrosis (SN) at 7 dpi, although not as pronounced as in other SN reactions, such as those attributed to Rvi8 (Vh8) (Bus et al., 2005a). The susceptible cultivars Gala, Minnewashta, and Minneiska showed no resistance reaction, only sporulating lesions.

chlorotic lesions with sporulation (3b-weak susceptibility), and lesions with high sporulation (4). $\mathrm{Fl}=$ auto-fluorescence, $\mathrm{SC}=$ stellate chlorosis, $\mathrm{SN}=$ stellate necrosis. *Observations of the cultivar Keepsake were made during the second and third replications

\begin{tabular}{|c|c|c|c|c|c|c|}
\hline \multirow[t]{2}{*}{ Cultivar } & \multicolumn{6}{|l|}{ Days Post Inoculation } \\
\hline & $1-3-5$ & 7 & 8 & 9 & 10 & 14 \\
\hline Frostbite & $\begin{array}{l}\text { Germinated spores, } \\
\text { appressorium }\end{array}$ & 2-3a-SC, Fl & 2-3a-SC, Fl & 2-3a-SC, Fl & 2-3a-SC, Fl & 2-3a-SC, Fl \\
\hline Northern Spy & “" & 2-3a-SN, Fl & 2-3a-SN, Fl & $2-3 \mathrm{a}-\mathrm{SN}, \mathrm{Fl}$ & $2-3 \mathrm{a}-\mathrm{SN}, \mathrm{Fl}$ & $2-3 \mathrm{a}-\mathrm{SN}, \mathrm{Fl}$ \\
\hline Keepsake* & ،“؛ & $\begin{array}{l}\text { Small lesions } \\
\text { 2-3a-SC, Fl }\end{array}$ & 2-3a-SC, Fl & 2-3a-SC, Fl & 2-3a-SC, Fl & 2-3a-SC, Fl \\
\hline Honeycrisp & ““吼 & $2-3 a-S C, F l$ & 2-3a-SC, Fl & $2-3 \mathrm{a}-\mathrm{SC}, \mathrm{Fl}$ & $\begin{array}{l}\text { 2-3a-SC; 3b-4; } \\
\text { necrosis, Fl }\end{array}$ & $\begin{array}{l}\text { 2-3a-SC; 3b-4; necrosis, } \\
\text { Sporulating, Fl }\end{array}$ \\
\hline Minnewashta & ‘“، & Sporulating & Sporulating & Sporulating & Sporulating & Sporulating \\
\hline Minneiska & ““ & Sporulating & Sporulating & Sporulating & Sporulating & Sporulating \\
\hline Royal Gala & ““ & Sporulating & Sporulating & Sporulating & Sporulating & Sporulating \\
\hline $\begin{array}{l}\text { Golden Delicious } \\
\quad(R V i l)\end{array}$ & ““" & $2-3 b, \mathrm{Fl}$ & $2-3 b, \mathrm{Fl}$ & $2-3 b, F l$ & $2-3 b, F l$ & 2-3b, Fl Sporulating \\
\hline $\begin{array}{l}\text { M. floribunda-821 } \\
\text { (Rvi6 Rvi7) }\end{array}$ & ““ & 0 & 0 & 0 & $1, \mathrm{Fl}$ & $1, \mathrm{Fl}$ \\
\hline Budagovsky 9 & 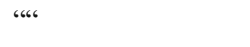 & Sporulating & Sporulating & Sporulating & Sporulating & Sporulating \\
\hline Pristine (Rviø) & ““ & 0 & 0 & 0 & 0 & No visible reaction \\
\hline
\end{tabular}


At 1-5 dpi, no auto-fluorescence was observed under ultraviolet light, even at the fungal penetration site. The susceptible reaction on 'Royal Gala' was primarily on the abaxial leaf surface. Figure 2 shows representative resistant $(\mathrm{A}-\mathrm{H})$ and susceptible (I-J) reactions of leaf tissue to the presence of the pathogen at several time points under brightfield and auto-fluorescence blue microscopy. At $10 \mathrm{dpi}$, small brown areas, presumably necrosis of the epidermal cells, were observed in bright-field observations of the resistance reactions. In a few localized lesions, extensive sporulation was also visible on 'Honeycrisp' under the dissecting microscope and in the cleared tissues at higher magnification (Figs. 3A, B; Fig. 4B).

As early as $7 \mathrm{dpi}$ and continuing through $14 \mathrm{dpi}$, the 'Honeycrisp', 'Keepsake', 'Frostbite' and 'Northern Spy' resistance reactions varied in size and shape, and were distinguished by auto-fluorescence primarily of epidermal cells surrounding the penetration site. Autofluorescence in the resistance reactions was independent from fluorescence in vascular tissue and cell walls normally produced by the plant. The reactions in 'Keepsake', 'Frostbite' and 'Northern Spy' were similar, consisting of browning of epidermal and mesophyll cells along the infection zone with stellate mycelial growth extending beyond the visible resistance reaction. Similar resistance responses were observed macro- and microscopically, except for 'Honeycrisp'. In the autofluorescence observations (Fig. 5), the 'Honeycrisp' resistance reactions were generally circular, with some evidence of necrotic tissue or browning of cells but not as extensive as typically observed in the classical HR. In addition to responses that completely restricted fungal invasion, there was evidence of some conidia establishing an infection site leading to sporulation. In cases where sporulation was visible $14 \mathrm{dpi}$ on 'Honeycrisp' leaves, auto-fluorescence was also detected (Figs. 3A, E). In addition to lesions caused by conidia, mycelia from the spore suspension were also observed to cause resistance reactions in the incompatible genotypes.

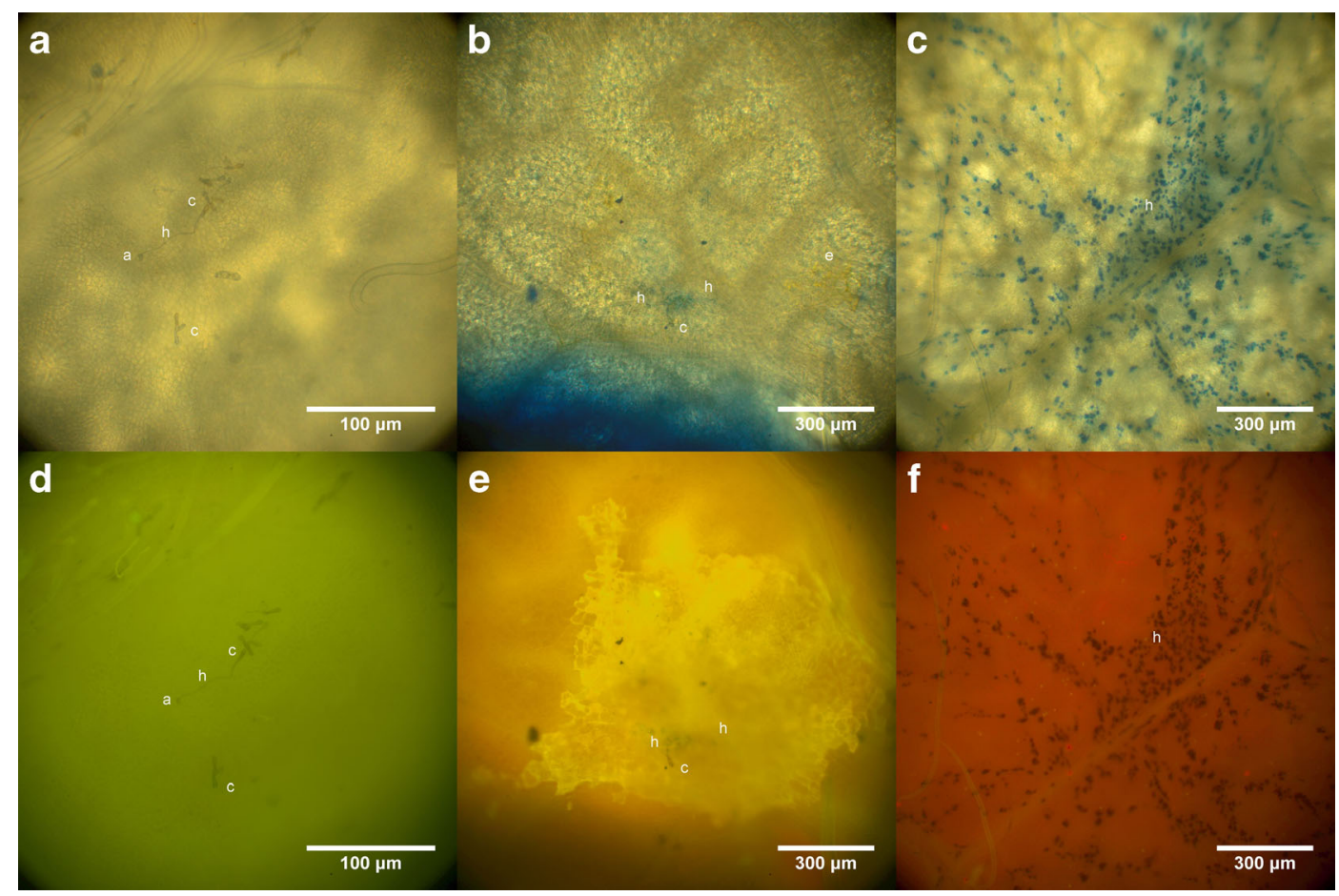

Fig. 2 Susceptible and resistant responses shown with brightfield $(\mathrm{A}, \mathrm{B}, \mathrm{C})$ and fluorescent $(\mathrm{D}, \mathrm{E}, \mathrm{F})$ microscopy. No difference in spore germination and appressoria development at 1,3, and 5 days post inoculation (dpi) between resistant and susceptible cultivars (A, D; 'Honeycrisp' shown at 5 dpi). Conidia (c), appressorium (a), germ tube (g), and hyphae (h) are labeled. Typical circular resistance response (B) in 'Honeycrisp' 8 dpi including browning of some epidermal cells (e) and auto-fluorescence of primarily epidermal cells (E). The compatible cultivar Minnewashta at 8 dpi exhibits copious sporulation of the pathogen stained blue (C) and only exhibits auto-fluorescence of vascular tissue and no resistance reaction $(\mathrm{F})$ 


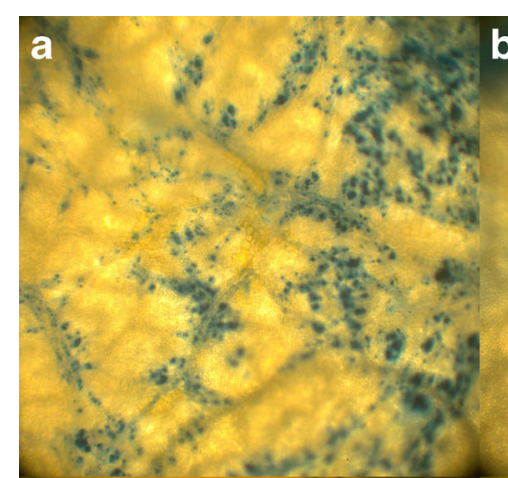

c

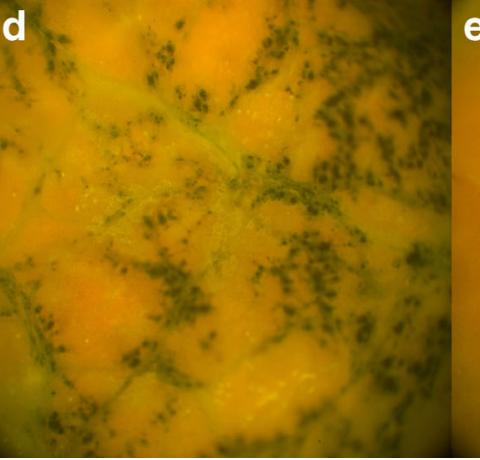

Fig. 3 Resistance reactions were varied within and across genotypes including sporulating lesions in 'Honeycrisp'. a Hyphae and conidia present (stained blue) in addition to browning of epidermal cells in 'Honeycrisp'. d Auto-fluorescence was evident in the host although sporulation was present. This may be due to mixed isolates which resulted in both compatible and incompatible reactions. b/e Stellate growth of the pathogen is apparent in 'Northern Spy', as well as a resistance reaction along the growth front as evidence by fluorescing cells. c/f Sporulating lesion in the susceptible cultivar Minnewashta shows numerous conidia and no evidence of auto-fluorescence

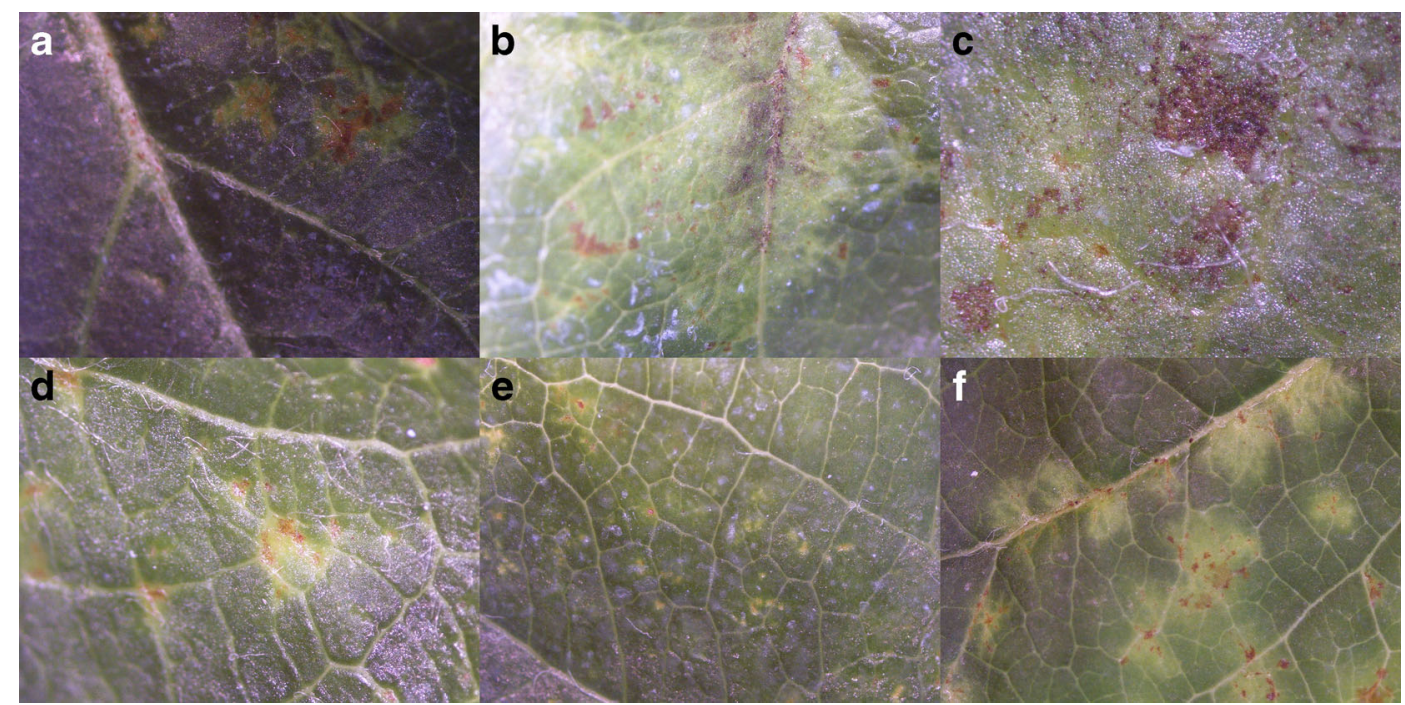

Fig. 4 Dissecting microscope photographs of resistance reaction in host plants 15 days post inoculation with mixed isolates of Venturia inaequalis. a 'Honeycrisp'with chlorotic flecking and necrosis. b 'Honeycrisp' with sporulating lesion and resistance reaction including necrosis. c Dense sporulating lesions in susceptible cultivar Minnewashta. d Resistance reaction in 'Northern Spy'. e 'Keepsake' exhibiting small lesions more macroscopically similar to the hypersensitive response with some necrosis. $\mathbf{f}$ Resistance reaction in 'Golden Delicious' 


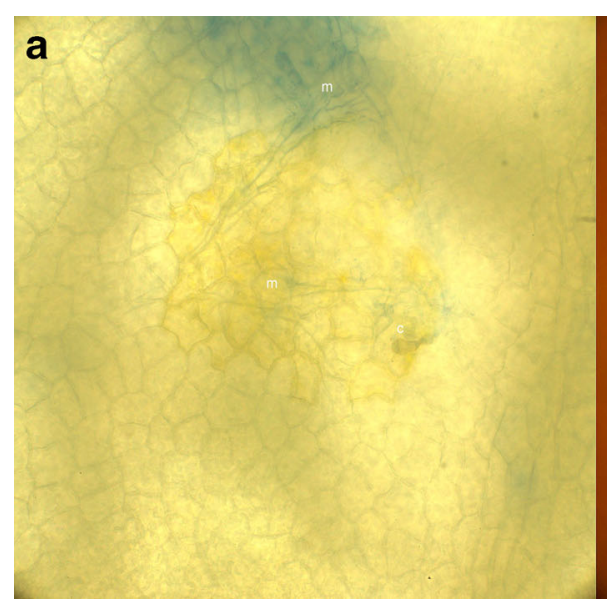

Fig. 5 Resistance reaction in 'Honeycrisp' to a suspension of mixed isolates of Venturia inaequalis 9 days post inoculation. Evidence of germinated condia (c) and mycelia ( $\mathrm{m}$; stained with aniline blue) that extends beyond the resistance reaction. (A)

\section{Experiment 2}

In numerous observations on two fungal isolates derived from 'Minneiska', the 'Honeycrisp' × 'Twin Bee Gala' progeny population demonstrated a range of resistance reactions along the six point scale (Chevalier et al., 1991). Fig. 6 show examples from a subset of resistance and susceptible phenotypes. The segregation of the symptom classes is shown in Table 3. The classic HR response was not observed in any of the progeny. Class 0 (no reaction) was common, even when individuals were screened numerous times with the same isolate to capture potential 'escapes' from the screening protocol. Stellate chlorosis and SN were observed in some of the progeny. The progeny population did not significantly

\section{b} Auto-fluorescence of epidermal cells at the infection site under interference blue microscopy

differ from $\mathrm{R}: \mathrm{S}=1: 1$ segregation when class $3 \mathrm{~b}$ was considered susceptible and 3 resistant : 1 susceptible when class $3 \mathrm{~b}$ was considered as resistant.

\section{Discussion}

The visible resistance reactions observed in 'Honeycrisp' appear approximately $7 \mathrm{dpi}$, at about the same time that susceptible reactions appear macroscopically. Up to that point, there are no observable macroscopic differences between compatible and incompatible reactions. From 1-5 dpi, germinating conidia and the development of appressoria were observed microscopically. In contrast to observations of Galli

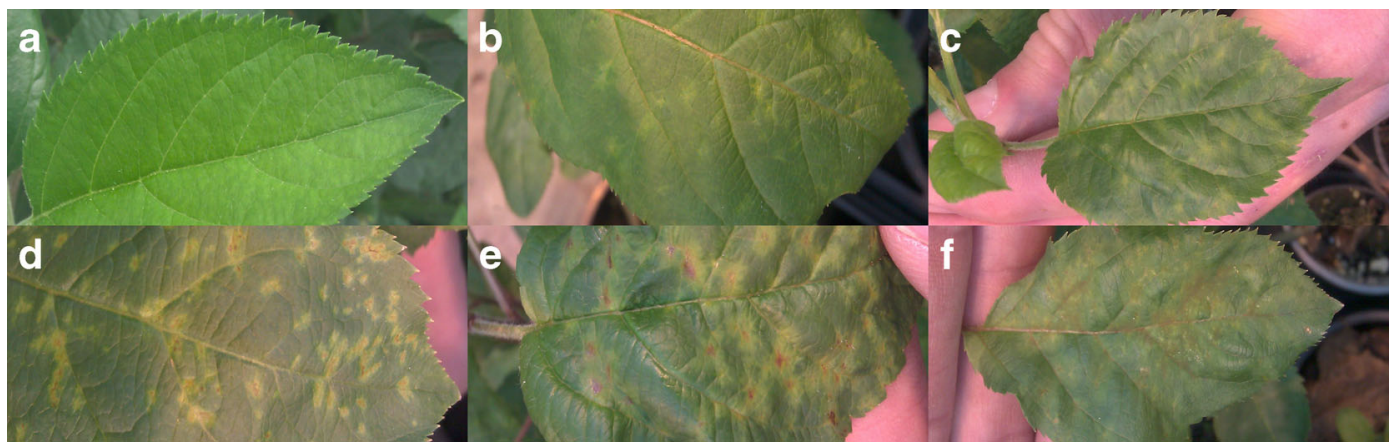

Fig. 6 Images demonstrating the range of observed phenotypic reactions classified according to Chevalier et al. (1991) in seedlings of a 'Honeycrisp' $x$ 'Twin Bee Gala' population utilized in mapping the 'Honeycrisp' resistance gene (s) to a single spore isolate (derived from 'Minneiska'). a Class 0 escape or no symptoms, b Class 2 chlorotic flecking, c/d Class 3A chlorosis, necrosis, light sporulation, e Class $3 \mathrm{~B}$ sporulation with cholorosis and necrosis, f Class 4 susceptible. No classic pin-point hypersensative response was observed 
Table 3 Segregation of apple scab resistance reactions in population AE1022 ('Honeycrisp' × 'Twin Bee Gala') when inoculated with two monoconidial isolates of Venturia inaequalis. The shaded boxes indicate categories included as resistant for calculating the segregation ratio (Resistant: Susceptible) and the $\chi^{2}$ with corresponding $p$ value is given. $\mathrm{SC}=$ stellate chlorosis

\begin{tabular}{|c|c|c|c|c|c|c|c|c|c|c|c|}
\hline \multirow[b]{2}{*}{ Isolate } & \multicolumn{8}{|c|}{ Resistance Class } & \multirow[b]{2}{*}{$\mathrm{R}: \mathrm{S}$} & \multirow[b]{2}{*}{$\chi^{2}$} & \multirow[b]{2}{*}{$p$} \\
\hline & 0 & 1 & 2 & $3 \mathrm{a}(\mathrm{SC})$ & $3 a-3 b$ & $3 b$ & $3 b-4$ & 4 & & & \\
\hline \multirow[t]{3}{*}{ 1914D } & 22 & 11 & 9 & $24(2)$ & 10 & 6 & 10 & 32 & $1: 1(68: 58)$ & 0.794 & $0.37 *$ \\
\hline & 22 & 11 & 9 & $24(2)$ & 10 & 6 & 10 & 32 & $3: 1(84: 42)$ & 4.667 & 0.03 \\
\hline & 22 & 11 & 9 & $24(2)$ & 10 & 6 & 10 & 32 & $3: 1(94: 32)$ & 0.011 & $0.92 * *$ \\
\hline \multirow[t]{3}{*}{ GR19142B } & 13 & 3 & 3 & 45 & 7 & 6 & 18 & 17 & $1: 1(64: 48)$ & 2.286 & $0.13^{*}$ \\
\hline & 13 & 3 & 3 & 45 & 7 & 6 & 18 & 17 & $3: 1(77: 35)$ & 2.333 & $0.13^{* *}$ \\
\hline & 13 & 3 & 3 & 45 & 7 & 6 & 18 & 17 & $3: 1(95: 17)$ & 5.762 & 0.06 \\
\hline
\end{tabular}

*A 1:1 segregation suggests the presence of one resistance gene in the population

**A 3:1 segregation suggests the presence of two resistance genes in the population

et al. (2010), in our study there was no evidence of autofluorescence directly at the infection site or along subcuticular mycelium in either reaction type before 7 dpi. The mixed inoculum was effective in eliciting compatible and incompatible reactions, which resulted in several resistance classes in 'Honeycrisp', including 2-3a with chlorotic flecking, stellate chlorosis and necrotic flecking, to $3 \mathrm{~b}$ with sporulation. These resistance reactions were also present in the ancestors and offspring. Stellate necrosis was present in 'Northern Spy' and in several of the 'Honeycrisp' $\times$ 'Twin Bee Gala' offspring. Resistance reactions were generally limited to the adaxial surface. In compatible reactions, sporulation was occasionally observed on the abaxial surface. What appeared to be necrotic flecking macroscopically was evidenced by browning and possible cell death of epidermal cells. The outer edges of epidermal cells and some mesophyll cells exhibited fluorescence, a key indicator of a defence response (Bus et al., 2005a).

The growth of subcuticular mycelia in incompatible reactions on 'Honeycrisp' was generally constrained to a circular resistance response. However, incompatible sporulating lesions (3b) and compatible (4) reactions were also observed. The reactions on 'Keepsake', 'Northern Spy' and 'Frostbite' exhibited stellate hyphal growth of the pathogen with corresponding resistance reactions along the growth front. The 'Honeycrisp' $\times$ 'Twin Bee Gala' progeny population segregated along the compatible-incompatible spectrum, except that no macroscopic class $1 \mathrm{HR}$ was observed. The interaction also required more time before macroscopic reactions were evident. This could be due to the different single spore isolates utilized as well as differences in greenhouse conditions between experiments.

Mixed inoculum was utilized to elucidate the resistance response, as to date there is no information about which of the physiologic scab race (s) are capable of causing infection in 'Honeycrisp'. This mixture was derived from a suspension of several single-spore isolates from varied host genotypes, which had been bulked-up on whole plants, from which leaves were stored at $-20^{\circ} \mathrm{C}$. These isolates had demonstrated efficacy in inciting infections and resistance reactions. To date, these isolates have not been assigned to physiologic races, limiting interpretation of the resulting incompatible plant-pathogen interactions within the GfG (or genes) model. Although derived from a 'Honeycrisp' fruit lesion, the positive control isolate $\mathrm{HC} 12 \mathrm{a}$ was not capable of inciting a compatible or incompatible reaction. Spores were present 1-3 dpi, but failed to germinate or develop appressoria, which suggests they may have been dead. The single spore isolate suspension was produced in axenic culture and had not been tested previously for its ability to cause infection.

The distinctly different resistance reactions in the 'Honeycrisp' ancestors ('Frostbite' 2-3a, 'Northern Spy' $2-3$ with $\mathrm{SN}$ ) and a 3:1 segregation ratio in the progeny population provides evidence for the possibility of two different major $\mathrm{R}$ genes inherited in 'Honeycrisp'. However, mapping experiments will be needed to test the hypothesis and trace the inheritance. In addition to different reaction types due to race specificity, other genetic factors within 'Honeycrisp' may be contributing to the range of resistance reactions 
observed in 'Honeycrisp' $\times$ 'Twin Bee Gala' progeny population. Macroscopic resistance reactions were difficult to categorize in some seedlings, whereas others exhibited clear, classic responses as described by Aldwinckle et al. (1976). The designation of reaction phenotypes into intermediate classes from $3 \mathrm{a}$ to $3 \mathrm{~b}$ to 4 macroscopically was difficult in seedlings. The class 0 reactions observed in the progeny may in fact be microscopic HR that affects a single or a very limited number of cells. Additional microscopic observations of the resistance reactions in the progeny population may provide better quantification of this trait. While such microscopic observations are labour intensive, the effort would be worthwhile for determining segregation of phenotypes in progeny populations for genetic mapping, but not for routine screening of seedling population. Alternatively, a recent report demonstrates the effectiveness of quantitative realtime polymerase chain reaction for detecting and quantifying the pathogen on leaf material and may serve as high-throughput tool for screening progeny (Gusberti et al., 2012).

The classification of 'Honeycrisp' and its ancestors and progeny into several resistance classes is similar to the diverse responses observed in Rvi6, Rvill and $R v i 12$, which also range from 0 to $3 \mathrm{~b}$ (Table 2). The lack of a HR as typical of resistance conditioned by Rvi4, Rvi5, and Rvi7 provides evidence that the resistance genes in 'Honeycrisp' are possibly unique. The time course from inoculation to the observation of macro- and microscopic reactions was also not as fast as the classic HR response, but was similar to reactions observed with Rvil5 inducing HR, which becomes visible at 7 dpi (Galli et al., 2010). In the Rvi15 resistance, fluorescence is limited to the browning epidermal and mesophyll cells that constitute the HR reaction (Galli et al., 2010). Stellate necrosis is associated with Rvi2and Rvi9-mediated resistance, and was first documented as an intermediate reaction by Shay and Hough (1952) at 4-6 dpi (Bus et al., 2005a). The stellate necrotic reaction observed in this experiment became visible after 7 dpi. The radial growth pattern of the pathogen was very apparent, as well as the resistance response along the lesion edge which included necrosis and fluorescence (Figs. 3B, E).

The range of resistance reactions, including sporulating lesions, on 'Honeycrisp' from a mixture of single spore isolates, highlights the importance of considering $\mathrm{R}$ genes within the GfG model. Furthermore, a single R gene cannot be considered a "silver bullet" providing permanent, i.e. durable, host immunity as the pathogen population is under selection pressure to evolve and circumvent host resistance. Consequently, the different isolates utilized in the experiments led to a range of defense responses within the same host. The 'Honeycrisp' resistance reaction is not a classic HR nor is there strong evidence for cell death beyond browning of epidermal cells in some reactions. These experiments support the model that resistance reactions are induced after penetration of the cuticle as the 'Honeycrisp' defence response initiated by the recognition of the pathogen effectors (AVR proteins) occurs 7 dpi well after the development of the fungal germ tube and appressorium. The variation in responses observed across the progeny population is evidence for minor genes or QTL that determine the resistant phenotype. These genes may result in different recognition mechanisms, recognition of non-specific elicitors, have altered signalling pathways or other genetic differences that alter the efficacy of pathogen recognition or the downstream response pathways (Heath, 2000). Signal molecules that may play a role include salicylic acid, jasmonic acid, reactive oxygen species, and nitric oxide (Richberg et al., 1998). The LRPKml gene in apple is involved in either detecting pathogen effectors or a plant signal that is the response of the defence cascade (Komjanc et al., 1999). Defence responses are more well-defined in model species like Arabidopsis thaliana (Glazebrook, 2001), in which the defence cascade and pathogen-induced gene regulation have been studied in gene expression experiments (Glazebrook et al., 2003). Resistant and susceptible apple cultivars have been shown to have differential gene expression when inoculated with $V$. inaequalis (Holzapfel et al. 2012). In infected apple leaves, the increased transcripts related to reactive oxygen species and oxidative burst are often implicated in PCD (Paris et al., 2009).

In addition to PCD, plants may inhibit the pathogen directly to prevent colonization. Pathogenesis related (PR) proteins, including chitinase, $\beta$-1,3-glucanase and cysteine-like protease, are similarly deployed in response to attack by $V$. inaequalis as well as P. leucotricha (powdery mildew; Gau et al., 2004). The resistant cultivar Remo demonstrated constitutive production of PR proteins in its leaves that were also detected in the susceptible cultivar Elstar only after it was inoculated with $P$. leucotricha and $V$. inaequalis (Gau et al., 2004). 
Auto-fluorescence under ultraviolet light has been used in several studies of the Malus-Venturia pathosystem to describe the incompatible reaction (Win et al., 2003; Bus et al., 2005a, 2010; Galli et al., 2010). Despite the clear visual clues provided by auto-fluorescence, little is known about the compounds involved in the resistance response. Fluorescent compounds often have rigid structures common to phenolic compounds involved in defence responses (Nicholson and Hammerschmidt, 1992; Davidson, 1996). Auto-fluorescence has been observed in other pathosystems and has been attributed to phytoalexin, amino acids, flavonoids, callose, and phenolic acids (Nicholson, 1977; Nicholson and Hammerschmidt, 1992; Dai et al., 1996; Jeun and Lee, 2005). In lettuce leaves infected with downy mildew, auto-fluorescence was attributed to the accumulation of ester-linked syringaldehyde and caffeic acid on plant cell walls, as well as the release of preformed phenolics from the vacuole in the HR (Bennett et al., 1996). Peroxidase plays a role in cell autofluorescence and browning that accompany HR as the result of oxidation of phenolic materials (Heath, 1998).

$\mathrm{R}$ proteins are defined as those involved in the recognition of the AVR signals (effectors) that activate the downstream responses through a signal cascade, which are distinct from the $\mathrm{R}$ protein itself. Variations in the expression of these genes may be expressed in variable resistance responses, and hence may explain the range of resistance symptoms observed in e.g. Rvi6 (Vf) as well as 'Honeycrisp' progeny populations. This agrees with Gardiner et al. (1996), who rejected the hypothesis that the range in Rvi6 phenotypes was a result of the loss of closely linked $\mathrm{R}$ genes as large portions of the donor genome (M. floribunda 821) were still intact around the locus after several generations of introgression into breeding lines. "Modifying genes" may also cause variations in the resistance expression of broad spectrum resistance loci to the extent that they are assigned to different resistance classes for a given $\mathrm{R}$ gene that is observed in a progeny population (Chevalier et al. 1991; Durel et al., 2004). The R:S=3:1 segregation ratio in the AE1022 population supports a model for two independent resistance genes being inherited from 'Honeycrisp'. Differences among individuals in the AE1022 population and in differential interactions within 'Honeycrisp' can be attributed to the monitoring of different effector proteins in the host by each $\mathrm{R}$ gene. Additional research will be required to elucidate the GfG interactions involved with these novel resistance genes.
Micro- and macroscopic characterization of the 'Honeycrisp' resistance reaction provides information for apple breeders and plant pathologists. This study demonstrated the cellular response in 'Honeycrisp' and its ancestors, and provides additional support for the presence of two underlying $\mathrm{R}$ genes, although it is unclear if these are contributed by 'Northern Spy' and/ or 'Frostbite'. The deployment of 'Honeycrisp' and its R genes may impact on the pathotype composition of pathogen populations in orchards. By documenting the resistance reaction in 'Honeycrisp', attempts can be made to monitor the development of virulent pathogens in 'Honeycrisp' orchards and the breakdown of resistance over time as evidenced by the gradual reduction in the intensity of the resistance response. The next step will be to include 'Honeycrisp' and its ancestors in the differential host set used for the worldwide monitoring of $V$. inaequalis pathotypes in trap orchards (Patocchi et al., 2009; www.vinquest.ch) for the identification in order to assess the potential of these resistance sources in cultivar breeding. The introgression of the 'Honeycrisp' R genes into new cultivars will require screening of seedling progenies with molecular markers to capitalize efficiently on the combinations of major and minor effect genes that impart the greatest levels of resistance that also is durable. Research on the mapping of the scab resistance of 'Honeycrisp' is in progress. The differential hosts will also be instrumental in confirming the GfG relationship between the complementary effector gene in the pathogen and the resistance gene in the host.

Acknowledgments The authors would like to thank Allison Wang for her assistance in isolating and maintaining $V$. inaequalis isolates. Ken Mullin and John Tillman assisted in plant maintenance, and greenhouse conditions were managed by Roger Meissner, Pam Warnke, and Dean Ziertman. Dr. Stefanie Dukowic-Schulze provided support in fluorescent microscope use and digital imaging.

Open Access This article is distributed under the terms of the Creative Commons Attribution License which permits any use, distribution, and reproduction in any medium, provided the original author(s) and the source are credited.

\section{References}

Aldwinckle, H. S., Gustafson, H. L., \& Lamb, R. C. (1976). Early determination of genotypes for apple scab resistance by forced flowering of test cross progenies. Euphytica, 25(1), 185-191. 
Barbara, D. J., Roberts, A. L., \& Xu, X.-M. (2008). Virulence characteristics of apple scab (Venturia inaequalis) isolates from monoculture and mixed orchards. Plant Pathol, 57(3), $552-561$.

Barnes, E. H., \& Williams, E. B. (1960). A biochemical response of apple tissues to fungus infection. Phytopathology, 50, 844-6.

Bénaouf, G., \& Parisi, L. (2000). Genetics of host-pathogen relationships between Venturia inaequalis races 6 and 7 and Malus species. Phytopathology, 90(3), 236-242.

Bennett, M., Gallagher, M., Fagg, J., Bestwick, C., Paul, T., Beale, M., et al. (1996). The hypersensitive reaction, membrane damage and accumulation of autofluorescent phenolics in lettuce cells challenged by Bremia lactucae. Plant J, 9(6), 851-865.

Berkett, L., M. Garcia, R. Moran, H. Darby, R. Parsons, J. Hayden, T. Bradshaw, S. Kingsley-Richards, and M. Cromwell. 2009. The OrganicA Project: Organic disease management in orchards with 'newer' cultivars. Int. Organ. Biol. Integr. Control Bull.: 428-432.

Boone, D. M. (1971). Genetics of Venturia inaequalis. Annu Rev Plant Physiol, 9(1), 297-318.

Bowen, J. K., Mesarich, C. H., Bus, V. G. M., Beresford, R. M., Plummer, K. M., \& Templeton, M. D. (2011). Venturia inaequalis: the causal agent of apple scab. Mol Plant Pathol, 12(2), 105-122.

Bus, V. G. M., Bassett, H. C. M., Bowatte, D., Chagné, D., Ranatunga, C. A., Ulluwishewa, D., et al. (2010). Genome mapping of an apple scab, a powdery mildew and a woolly apple aphid resistance gene from open-pollinated mildew immune selection. Tree Genet Genome, 6(3), 477-487.

Bus, V. G. M., Laurens, F. N. D., Van De Weg, W. E., Rusholme, R. L., Rikkerink, E. H. A., Gardiner, S. E., et al. (2005a). The Vh8 locus of a new gene-for-gene interaction between Venturia inaequalis and the wild apple Malus sieversii is closely linked to the Vh2 locus in Malus pumila R127407A. New Phytol, 166(3), 1035-1049.

Bus, V. G. M., Rikkerink, E. H. A., Caffier, V., Durel, C. E., \& Plummer, K. M. (2011). Revision of the nomenclature of the differential host-pathogen interactions of Venturia inaequalis and Malus. Annu Rev Phytopathol, 49(1), 391-413.

Bus, V. G. M., Rikkerink, E. H. A., van de Weg, W. E., Rusholme, R. L., Gardiner, S. E., Bassett, H. C. M., et al. (2005b). The $V h 2$ and $V h 4$ scab resistance genes in two differential hosts derived from Russian apple R12740-7A map to the same linkage group of apple. Mol Breeding, 15(1), 103-116.

Cabe, P. R., Baumgarten, A., Onan, K., Luby, J. J., \& Bedford, D. S. (2005). Using microsatellite analysis to verify breeding records: a study of 'Honeycrisp' and other cold-hardy apple cultivars. HortSci, 40(1), 15-17.

Chevalier, M., Lespinasse, Y., \& Renaudin, S. (1991). A microscopic study of the different classes of symptoms coded by the Vf gene in apple for resistance to scab (Venturia inaequalis). Plant Pathol, 40(2), 249-256.

Dai, G. H., Nicole, M., Andary, C., Martinez, C., Bresson, E., Boher, B., et al. (1996). Flavonoids accumulate in cell walls, middle lamellae and callose-rich papillae during an incompatible interaction between Xanthomonas campestris pv. malvacearum and cotton. Physiol. Mol. Plant Pathol, 49(5), 285-306.

Dangl, J. L., \& Jones, J. D. G. (2001). Plant pathogens and integrated defence responses to infection. Nature, 411(6839), 826-833.
Davidson, R. S. (1996). Application of fluorescence microscopy to a study of chemical problems. Chem Soc Rev, 25(4), 241253.

Dunemann, F., \& Egerer, J. (2010). A major resistance gene from Russian apple 'Antonovka' conferring field immunity against apple scab is closely linked to the $V f$ locus. Tree Genet Genome, 6(5), 627-633.

Durel, C. E., Calenge, F., Parisi, L., Weg, W. E., Kodde, L. P., Crassweller, R., et al. (2004). An overview of the position and robustness of scab resistance QTLs and major genes by aligning of genetic maps in five apple progenies. Acta Horticult, 663, 135-140.

Flor, H. H. (1956). The complementary genic system in flax and flax rust. Adv Genet, 8, 29-54.

Galli, P., Broggini, G. A. L., Gessler, C., \& Patocchi, A. (2010). Phenotypic characterization of the Rvi15 $(V r 2)$ apple scab resistance. J Plant Pathol, 92(1), 219-226.

Gardiner, S. E., Bassett, H. C. M., Noiton, D. A. M., Bus, V. G. M., Hofstee, M. E., White, A. G., et al. (1996). A detailed linkage map around an apple scab resistance gene demonstrates that two disease resistance classes both carry the $V f$ gene. Theor Appl Genet, 93(4), 485-493.

Gau, A. E., Koutb, M., Piotrowski, M., \& Kloppstech, K. (2004). Accumulation of pathogenesis-related proteins in the apoplast of a susceptible cultivar of apple (Malus domestica cv. Elstar) after infection by Venturia inaequalis and constitutive expression of PR genes in the resistant cultivar Remo. Eur. J. Plant Pathol, 110(7), 703-711.

Gessler, C. (1992). Scab resistance in apple: the minor genes in the $V f$-resistance. Acta Phytopathol et Entomolog Hung, 27, 257-263.

Gessler, C., Patocchi, A., Sansavini, S., Tartarini, S., \& Gianfranceschi, L. (2006). Venturia inaequalis resistance in apple. Crit Rev Plant Sci, 25(6), 473-503.

Gessler, C., \& Stumm, D. (1984). Infection and stromal formation by Venturia inaequalis on apple leaves with different degrees of susceptibility to scab. J. Phytopathol, 110(2), 119-126.

Glazebrook, J. (2001). Genes controlling expression of defense responses in Arabidopsis - 2001 status. Curr Opin Plant Biol, 4(4), 301-308.

Glazebrook, J., Chen, W., Estes, B., Chang, H.-S., Nawrath, C., Métraux, J.-P., et al. (2003). Topology of the network integrating salicylate and jasmonate signal transduction derived from global expression phenotyping. Plant J, 34(2), 217228.

Goodman, R. N., \& Novacky, A. J. (1994). The hypersensative reaction in plants to pathogens: a resistance phenomenon. St. Paul: APS Press.

Gusberti, M., Patocchi, A., Gessler, C., \& Broggini, G. A. L. (2012). Quantification of Venturia inaequalis growth in Malus $\times$ domestica with quantitative real-time polymerase chain reaction. Plant Dis, 96(12), 1791-1797.

Heath, M. C. (1998). Involvement of reactive oxygen species in the response of resistant (hypersensitive) or susceptible cowpeas to the cowpea rust fungus. New Phytol, 138(2), 251263.

Heath, M. C. (2000). Hypersensitive response-related death. Plant Mol Biol, 44(3), 321-334.

Heath, M. C., Nimichuk, Z. L., \& Xu, H. (1997). Plant nuclear migrations as indicators of critical interactions between resistant or susceptible cowpea epidermal cells and invasion 
hyphae of the cowpea rust fungus. New Phytol, 135(4), 689700.

Holzapfel, C., Meisel, B., Thümmler, F., Leser, C., \& Treutter, D. (2012). Differential gene expression in leaves of a scab susceptible and a resistant apple cultivar upon Venturia inaequalis inoculation. Trees, 26(1), 121-129.

Jeun, Y.-C., \& Lee, K.-H. (2005). Observations of infection structures after inoculation with Colletotrichum orbiculare on the leaves of cucumber plants pre-inoculated with two bacterial strains Pseudomonas putida or Micrococcus luteus. Mycobiology, 33(3), 131.

Jha, G., Thakur, K., \& Thakur, P. (2009). The Venturia apple pathosystem: pathogenicity mechanisms and plant defense responses. Biotechnol: J. Biomed.

Komjanc, M., Festi, S., Rizzotti, L., Cattivelli, L., Cervone, F., \& De Lorenzo, G. (1999). A leucine-rich repeat receptor-like protein kinase (LRPKm 1$)$ gene is induced in Malus $\times$ domestica by Venturia inaequalis infection and salicylic acid treatment. Plant Mol Biol, 40(6), 945-957.

Lamb, R. C., \& Hamilton, J. M. (1969). Environmental and genetic factors influencing the expression of resistance to scab (Venturia inaequalis Cke. Want.) in apple progenies. $J$ Amer Soc Hort Sci, 94, 554-557.

Nicholson, R.L. 1977. Host-pathogen interactions preceding the hypersensitive reaction of Malus sp. to Venturia inaequalis. Phytopathology 77 (1): 108.

Nicholson, R. L., \& Hammerschmidt, R. (1992). Phenolic compounds and their role in disease resistance. Annu Rev Phytopathol, 30(1), 369-389.

Nicholson, R. L., Van Scoyoc, S., \& Williams, E. B. (1973). Response of detached apple leaves to Venturia inaequalis. Phytopathology, 63, 649-650.

Nusbaum, C. J., \& Keitt, G. W. (1938). A cytological study of host-parasite relations of Venturia inaequalis on apple leaves. J Agric Res, 56, 595-618.
Paris, R., Cova, V., Pagliarani, G., Tartarini, S., Komjanc, M., \& Sansavini, S. (2009). Expression profiling in HcrVf2-transformed apple plants in response to Venturia inaequalis. Tree Genet Genome, 5(1), 81-91.

Parker, D. M., Hilber, U. W., Bodmer, M., Smith, F. D., Yao, C., \& Köller, W. (1995). Production and transformation of conidia of Venturia inaequalis. Phytopathology, 85(1), 87-91.

Patocchi, A., Frei, A., Frey, J. E., \& Kellerhals, M. (2009). Towards improvement of marker assisted selection of apple scab resistant cultivars: venturia inaequalis virulence surveys and standardization of molecular marker alleles associated with resistance genes. Mol Breed, 24, 337-347.

Richberg, M. H., Aviv, D. H., \& Dangl, J. L. (1998). Dead cells do tell tales. Curr Opin Plant Biol, 1(6), 480-485.

Schneider, C. A., Rasband, W. S., \& Eliceiri, K. W. (2012). NIH Image to ImageJ: 25 years of image analysis. Nat Methods, 9, 671-675.

Shay, J. R., \& Hough, L. F. (1952). Evaluation of apple scab resistance in selections of Malus. Am J Bot, 39(4), 288-297.

Valsangiacomo, C., \& Gessler, C. (1988). Role of the cuticular membrane in ontogenic and $V$ f-resistance of apple leaves against Venturia inaequalis. Phytopathology, 78, 1066-1068.

Vanderplank, J.E. 1978. Genetic and molecular basis of plant pathogenesis. 6: $167 \mathrm{pp}$.

Vanderplank, J. E. (1982). Host-pathogen interactions in plant disease. New York: Academic.

Voorrips, R. E., Bink, M. C. A. M., \& van de Weg W. E. (2012). Pedimap: software for the visualization of genetic and phenotypic data in pedigrees. J Hered, 103(6), 903-907.

Williams, E. B., \& Kuc, J. (1969). Resistance in Malus to Venturia inaequalis. Annu Rev Phytopathol, 7(1), 223-246.

Win, J., Greenwood, D. R., \& Plummer, K. M. (2003). Characterisation of a protein from Venturia inaequalis that induces necrosis in Malus carrying the Vm resistance gene. Physiol Mol Plant Pathol, 62(4), 193-202. 